\title{
THE LMA PROSEAL: AN EFFECTIVE ALTERNATIVE TO TRACHEAL INTUBATION FOR LAPAROSCOPIC CHOLECYSTECTOMY
}

\author{
Sanchita Sarma Borkataki¹, D. G. Pathak², Bandana Mahanta3, Dipika Choudhury4 \\ ${ }^{1}$ Assistant Professor, Department of Anaesthesiology \& Critical Care, Gauhati Medical College \& Hospital. \\ 2 Professor and HOD, Department of Anaesthesiology \& Critical Care, Silchar Medical College \& Hospital. \\ ${ }^{3}$ Associate Professor, Department of Anaesthesiology \& Critical Care, Tezpur Medical College \& Hospital. \\ ${ }^{4}$ Professor and HOD, Department of Anaesthesiology \& Critical Care, Gauhati Medical College \& Hospital.
}

\section{ABSTRACT}

An Anaesthesiologist has the fundamental responsibility to maintain a patent airway during surgical procedures. Although the tracheal tube is considered ideal for laparoscopic procedures, there is consistent flow of reports highlighting the safety of LMA ProSeal in laparoscopic surgeries. The aim of this study was to compare the effects of insertion and removal of LMA ProSeal and Endotracheal tube on haemodynamic responses, to evaluate the efficacy and safety of use of LMA ProSeal as an airway device for Laparoscopic cholecystectomy and to note other observations, if any. Sixty patients undergoing elective Laparoscopic Cholecystectomy of 35-45 minutes duration were randomly divided into two groups comprising of 30 patients in each.

Group E: Patients receiving EndoTracheal Tube (ETT).

Group P: Patients receiving LMA ProSeal (LMA-PS).

A standard General Anaesthesia protocol and routine monitoring was applied in all patients. Monitoring of Heart Rate (HR), Systolic Blood Pressure (SBP), Diastolic Blood Pressure (DBP), Mean Arterial Blood Pressure (MAP) and SP02 preoperatively (As baseline), after intubation or placement of LMA-PS, at $1 \mathrm{~min}, 3 \mathrm{mins}, 5 \mathrm{mins}$ and every $5 \mathrm{mins}$ thereafter till the reading at removal and after 5 mins of removal of ETT or LMA-PS. For both the groups, baseline value for ETCO2 was taken from connection of ETCO2 cable following placement of airway devices (ETT/LMA-PS).All data were analyzed by specific statistical methods applicable to the various sets of data. Tests employed were Student T test, Fisher's exact test which were performed on SPSS software. Microsoft Word and Excel have been used to generate graphs, tables etc. SpO2 was well maintained in both the groups throughout the procedure. On statistical analysis, it was found that the increase in HR,SBP,DBP, MAP were highly significant after instrumentation, at 1 min and 3 mins with Group E showing a greater rise than Group P. It became insignificant at 5 mins and there after throughout the procedure. At removal also the HR, SBP, DBP, MAP were significantly more with ETT than LMA-PS. ETCO2 was well maintained in both the groups throughout the procedure. Incidence of sore throat after removal in both ETT and LMA-PS group was statistically insignificant $(\mathrm{P}>0.05)$. Clinically detectable aspiration and gastric distension was not observed in any case in both the groups. In experienced hands and following a strict protocol of insertion, the LMA-PS has been proved to be an efficient and safe tool for airway management of elective patients undergoing laparoscopic cholecystectomy.

\section{KEYWORDS}

Endotracheal Intubation, Haemodynamic Responses, IPPV, Laparoscopic Cholecystectomy, LMA ProSeal.

HOW TO CITE THIS ARTICLE: Borkataki SS, Pathak DG, Mahanta B, et al. "The LMA proseal: an effective alternative to tracheal intubation for laparoscopic cholecystectomy." Journal of Evolution of Medical and Dental Sciences 2015; Vol. 4, Issue 105, December 31; Page: 17066-17073, DOI: 10.14260/jemds/2015/2586

\section{INTRODUCTION}

Endotracheal intubation is one of the most significant developments of Anaesthesia for maintenance of airway and is considered one of the best ways for securing the airway. Though the discovery of Endotracheal tube is a great achievement, it is not free from complexities. The most important being the deleterious haemodynamic consequences in response to laryngoscopy and intubation due to reflex sympathoadrenal stimulation. ${ }^{1}$

The major cause of sympathoadrenal response to tracheal intubation is due to the stimulation of supraglottic region by tissue irritation induced by direct laryngoscopy. ${ }^{2}$

Financial or Other, Competing Interest: None.

Submission 07-12-2015, Peer Review 08-12-2015,

Acceptance 28-12-2015, Published 31-12-2015.

Corresponding Author:

Dr. Sanchita Sarma Borkataki,

Assistant Professor,

Department of Anaesthesiology \& Critical Care,

Gauhati Medical College \& Hospital,

Guwahati, Assam.

E-mail: sbsarma1@gmail.com

DOI:10.14260/jemds/2015/2586
Insertion of the Endotracheal tube through the vocal cords and inflation of the cuff in the infraglottic region is regarded to contribute very little stimulation.

Direct laryngoscopy by activating proprioceptors, induces arterial hypertension, tachycardia and increased catecholamine concentration proportional to the intensity of stimulus exerted against the base of the tongue. ${ }^{3}$ Subsequent tracheal intubation should stimulate additional receptors in the larynx and trachea, thus enhancing the haemodynamic responses. ${ }^{4}$

The use of LMA is one of the most promising nonpharmacological method to attenuate the sympathoadrenal response to tracheal intubation, as its insertion requires neither the visualization of the vocal cords nor penetration of the larynx, thus causing less sympathetic response and catecholamine release. ${ }^{5}$

The LMA ProSeal is a modification of the LMA Classic (CLMA) and is becoming popular as it is specially designed for positive pressure ventilation and protection against aspiration. The flexible and non-kinkable airway tube of LMA ProSeal increases its safety. 


\section{MATERIALS AND METHODS}

After approval of the Institutional Ethical Committee and written informed consent, 102 patients were done according to the study protocol out of which 60 cases which met all the inclusion criteria were selected for the study. Sixty cases undergoing elective Laparoscopic Cholecystectomy of 35-45 minutes duration, were randomly divided into two groups comprising of 30 patients in each group.

Group E: Patients receiving EndoTracheal Tube (ETT)

Group P: Patients receiving LMA ProSeal (LMA-PS); for airway management.

\section{Inclusion Criteria}

- Patients of ASA I and II.

- Only elective cases.

- Age of 20 to 50 years.

- Patients of both sexes.

- Laparoscopic cholecystectomy cases of 35-45 minutes duration were only included in the study.

\section{Exclusion Criteria}

- Patients of ASA > II.

- Emergency cases.

- Age $<20$ years or $>50$ years.

- Obese patients.

- Full stomach.

- Anticipated difficult airway.

- More than one attempt at placement of the airway device.

- More than 30 secs required for laryngoscopy and intubation.

- Cases of duration less than 35 minutes and more than 45 minutes were excluded from the study.

\section{Patients Having Following Diseases were also Excluded}

- Gastroesophageal reflux.

- Hiatus hernia.

- Oesophageal diseases.

- Chronic obstructive pulmonary disease.

- Drug allergy.

- Cardiovascular disease.

- Bleeding disorders.

- Pregnant patient.

\section{TECHNIQUE}

A pre-operative check-up was done on the previous night of the day of surgery. Demographic data, physical examination findings and laboratory investigations were recorded systemically in the proforma. Fasting was advised as per ASA guideline. Written informed consent was taken.

All the patients were given Tab. Alprazolam $(0.5 \mathrm{mg})$ and Tab. Ranitidine $(300 \mathrm{mg})$ on the previous night of surgery. On the day of operation, patients were again examined and shifted to the operation theatre. Intra-venous line was established with 18 G IV cannula and all monitors like non-invasive blood pressure, electrocardiography and pulse-oximeter were attached to each patient.

All patients received similar premedication with intravenous Midazolam $0.02 \mathrm{mg} / \mathrm{kg}$, Ranitidine $50 \mathrm{mg}$, Metoclopramide $10 \mathrm{mg}$. Glycopyrrolate $0.005 \mathrm{mg} / \mathrm{kg}$ and Inj. Fentanyl $1.5 \mathrm{mcg} / \mathrm{kg}$. A standard General Anaesthesia technique was adopted in all patients consisting of preoxygenation for 3 minutes, induction with Inj. Lidocaine (2\%) $20 \mathrm{mg}$ and Inj. Propofol $1 \%(2 \mathrm{mg} / \mathrm{kg})$ followed by Inj. Rocuronium $(0.9 \mathrm{mg} / \mathrm{kg})$ intravenously. Then patients were ventilated with $100 \%$ oxygen for 1 minute. Before insertion, in both the airway devices, the cuff was fully deflated and clear water based jelly was used to lubricate the posterior aspect of the cuff.

In Group E, PVC cuffed ETT of size $7.5 \mathrm{~mm}, 8 \mathrm{~mm}$ and $8.5 \mathrm{~mm}$ were used for both sexes as required, for intubation following direct laryngoscopy. The cuff was inflated until no leak was audible.

In Group P, patients received LMA-PS, size 3 and size 4 (as per body weight) by digital technique. The cuff was inflated with just less than $20 \mathrm{ml}$ and $30 \mathrm{ml}$ air for size 3 and size 4 LMA$\mathrm{PS}$ respectively.

\section{Correct Placement of both ETT and LMA-PS was confirmed} by,

1. Observing chest movement.

2. Bilateral chest auscultation.

3. ETCO2 waveform by manual ventilation.

4. Easy passage of the Ryle's tube through the gastric tube indicates correct positioning (in case of LMA-PS).

5. If the midpoint of the bite block (in case of LMA-PS), was just proximal to the incisors, the LMA-PS was taken to be correctly positioned.

Then both the devices were secured with adhesive tape. A Ryle's tube (14-French) was passed in every patient of both groups. The Ryle's tube was connected to suction machine to facilitate suction of the gastric content whenever necessary.

Anaesthesia was maintained with $0.5 \%$ Isoflurane and Nitrous oxide (67\% approx.) in 33\% Oxygen. Neuromuscular blockade was maintained with Inj. Rocuronium with top up of $10 \mathrm{mg}$ when needed. Ventilation was set at a tidal volume of $8 \mathrm{ml} / \mathrm{kg}$, respiratory rate of $12-14 / \mathrm{min}$ and $\mathrm{I} / \mathrm{E}$ ratio of $1: 2$.

The surgeon inserted a trocar into the peritoneal cavity under direct vision. Peritoneal insufflation (with $\mathrm{CO}_{2}$ ) pressure was preset and maintained at $12 \mathrm{mmHg}$. Head-up and lateral tilt were provided at the surgeon's request. After the completion of surgery, neuromuscular blockade was reversed with Inj. Neostigmine $(0.05 \mathrm{mg} / \mathrm{kg})$ and Inj. Glycopyrrolate $(0.01 \mathrm{mg} / \mathrm{kg})$.

Monitoring of $\mathrm{HR}, \mathrm{SBP}, \mathrm{DBP}, \mathrm{MAP}$ and $\mathrm{SPO}_{2}$ preoperatively (As baseline), after intubation or placement of LMA-PS, at $1 \mathrm{~min}$, $3 \mathrm{mins}$, $5 \mathrm{mins}$ and every $5 \mathrm{mins}$, thereafter till the reading at removal and after 5 mins of removal of ETT or LMA-PS. For both the groups, baseline value for $\mathrm{ETCO}_{2}$ was taken from connection of $\mathrm{ETCO}_{2}$ cable following placement of airway devices (ETT/LMA-PS).

\section{STATISTICAL ANALYSIS}

All data were analysed by specific statistical methods applicable to the various sets of data. Tests employed were Student T test, Fisher's exact test which were performed on SPSS software. Microsoft Word and Excel have been used to generate graphs, tables, etc.

$$
\begin{aligned}
\mathrm{P} \text { value: } & >0.05=\text { not significant } \\
& <0.05=\text { significant } \\
& <0.01=\text { highly significant }
\end{aligned}
$$




\section{RESULTS AND OBSERVATIONS}

A total of sixty elective, normotensive adult patients were taken for this study, where the cardiovascular changes, efficacy of positive pressure ventilation, emergence and complications if any were observed and compared between patients receiving ETT and LMA-PS taken up for laparoscopic cholecystectomy of duration 35 to $45 \mathrm{~min}$.

The effects were observed by monitoring heart rate, blood pressure, and $\mathrm{SPO}_{2}$ preoperatively (As baseline), after intubation or placement of LMA-PS, at $1 \mathrm{~min}, 3 \mathrm{mins}, 5 \mathrm{mins}$ and every 5 mins thereafter till the reading at removal and after 5 mins of removal of ETT or LMA-PS. For both the groups, baseline value for $\mathrm{ETCO}_{2}$ was taken from connection of $\mathrm{ETCO}_{2}$ cable following placement of airway devices (ETT/ LMA-PS)

The Patients were Randomly Divided into Two Groups comprising of 30 Patients in Each Group.

Group E: Patients receiving EndoTracheal Tube (ETT) for airway management.

Group P: Patients receiving LMA ProSeal (LMA-PS) for airway management.

The observations were compiled and the results were analysed statistically. The Observations are tabulated as

(I) Demographic Variables

(I) Age distribution

(II) Weight

(III) Sex

(IV) ASA status

(V) MPS

(II) Haemodynamic Variables

(I) Heart Rate (HR)

(II) Systolic Blood Pressure (SBP)

(III) Diastolic Blood Pressure (DBP)

(IV) Mean Arterial Pressure (MAP)

(III) For Ventilation

(I) $\mathrm{SPO}_{2}$

(II) $\mathrm{ETCO}_{2}$

(IV) Complications

1. Sore throat

2. Gastric distension

3. Aspiration

One hundred and two patients were done according to the study protocol out of which 60 cases which met all the inclusion criteria were selected for the study. The two groups were comparable in terms of age, weight, sex, ASA physical status grading, Mallampati Scoring (MPS) and duration of surgery, as can be seen in Tables I, II, III and IV.

\begin{tabular}{|c|c|c|c|c|}
\hline Group & $\begin{array}{c}\text { Number } \\
\text { of Cases }\end{array}$ & $\begin{array}{c}\text { Mean Age } \\
\mathbf{\pm S . D}\end{array}$ & $\begin{array}{c}\text { Mean } \\
\text { Weight } \\
\mathbf{\pm S . D}\end{array}$ & $\begin{array}{c}\text { Sex } \\
\text { (M:F) }\end{array}$ \\
\hline $\begin{array}{c}\text { Group } \\
\text { E }\end{array}$ & 30 & $\begin{array}{c}36.6 \pm \\
11.12\end{array}$ & $51.9 \pm 6.42$ & $\begin{array}{c}11: \\
19\end{array}$ \\
\hline $\begin{array}{c}\text { Group } \\
\text { P }\end{array}$ & 30 & $\begin{array}{c}37.2 \pm \\
12.10\end{array}$ & $52.8 \pm 6.48$ & $\begin{array}{c}12: \\
18\end{array}$ \\
\hline \multicolumn{4}{|c|}{ Table 1 } \\
\hline
\end{tabular}

\begin{tabular}{|c|c|c|}
\hline & \multicolumn{2}{|c|}{ ASA grade } \\
\hline Group & I & II \\
\hline E(ETT) & 21 & 9 \\
\hline P(LMA-PS) & 21 & 9 \\
\hline Total & 42 & 18 \\
\hline \multicolumn{2}{|c}{ Table 2 } \\
\hline
\end{tabular}

$* \mathrm{P}>0.05$

Fisher's exact test

\begin{tabular}{|c|c|c|}
\hline & \multicolumn{2}{|c|}{ MPS } \\
\hline Group & I & II \\
\hline E(ETT) & 18 & 12 \\
\hline P(LMA-PS) & 16 & 14 \\
\hline Total Table 3 & $\mathbf{3 4}$ & $\mathbf{2 6}$ \\
\hline \multicolumn{2}{|c|}{} \\
\hline \multicolumn{2}{|c|}{}
\end{tabular}

${ }^{*} \mathrm{P}>0.05$

Fisher's exact test

In both the groups operative procedure was Laparoscopic cholecystectomy.

\begin{tabular}{|c|c|c|c|}
\hline & \multicolumn{3}{|c|}{ Duration of Surgery } \\
\hline Group & 35mins & 40mins & 45mins \\
\hline E & 11 & 12 & 7 \\
\hline P & 12 & 10 & 8 \\
\hline \multicolumn{4}{|c|}{ Table 4 } \\
\hline
\end{tabular}

From Graph-1, on statistical analysis, it was found that the heart rate variation was highly significant at placement of ETT compared to LMA-PS, at 1 min and 3 mins. At 5 mins the variation of heart rate was significant, after which it was not significant throughout the procedure till removal of the airway devices. At removal the rise in mean HR was significantly more with ETT than LMA-PS.

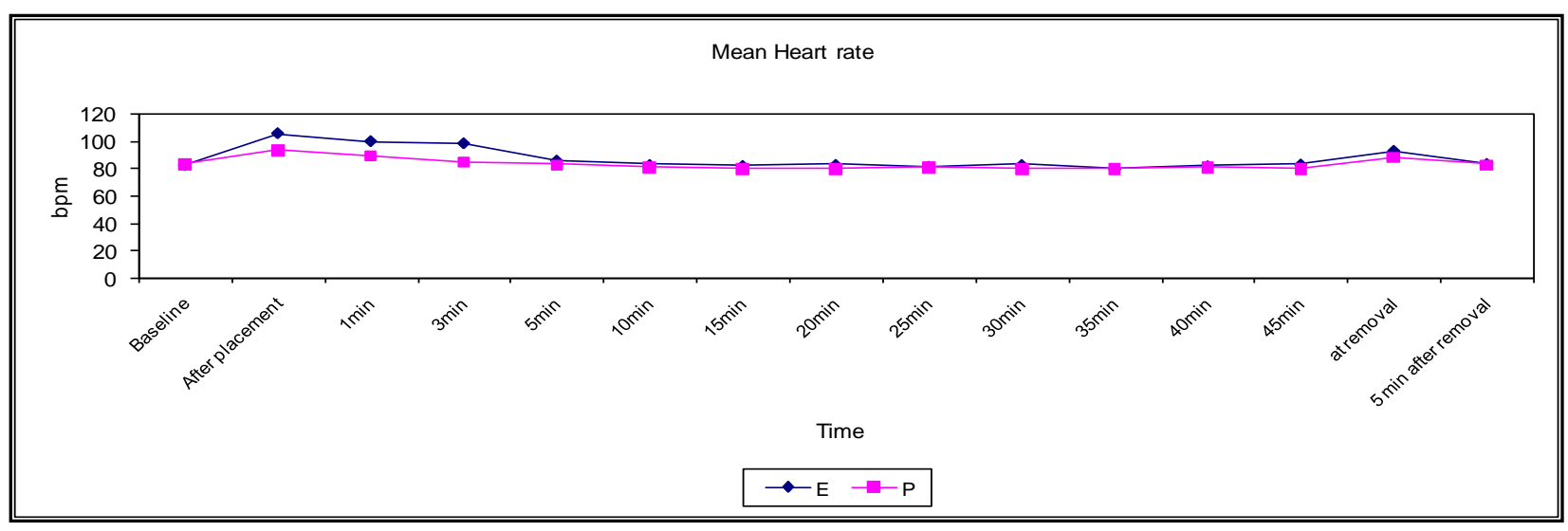

Graph 1: HR Variation-Both the Groups 
From Graph 2, 3, 4 on comparison of the two groups, it was found that there was highly significant increase in SBP, DBP, MAP after instrumentation at $1 \mathrm{~min}$ and 3 mins with Group E showing a greater rise than Group P; which became insignificant at 5 mins and thereafter throughout the procedure till removal of airway devices. At removal the rise in mean SBP, DBP, MAP were significantly more with ETT than LMA-PS.

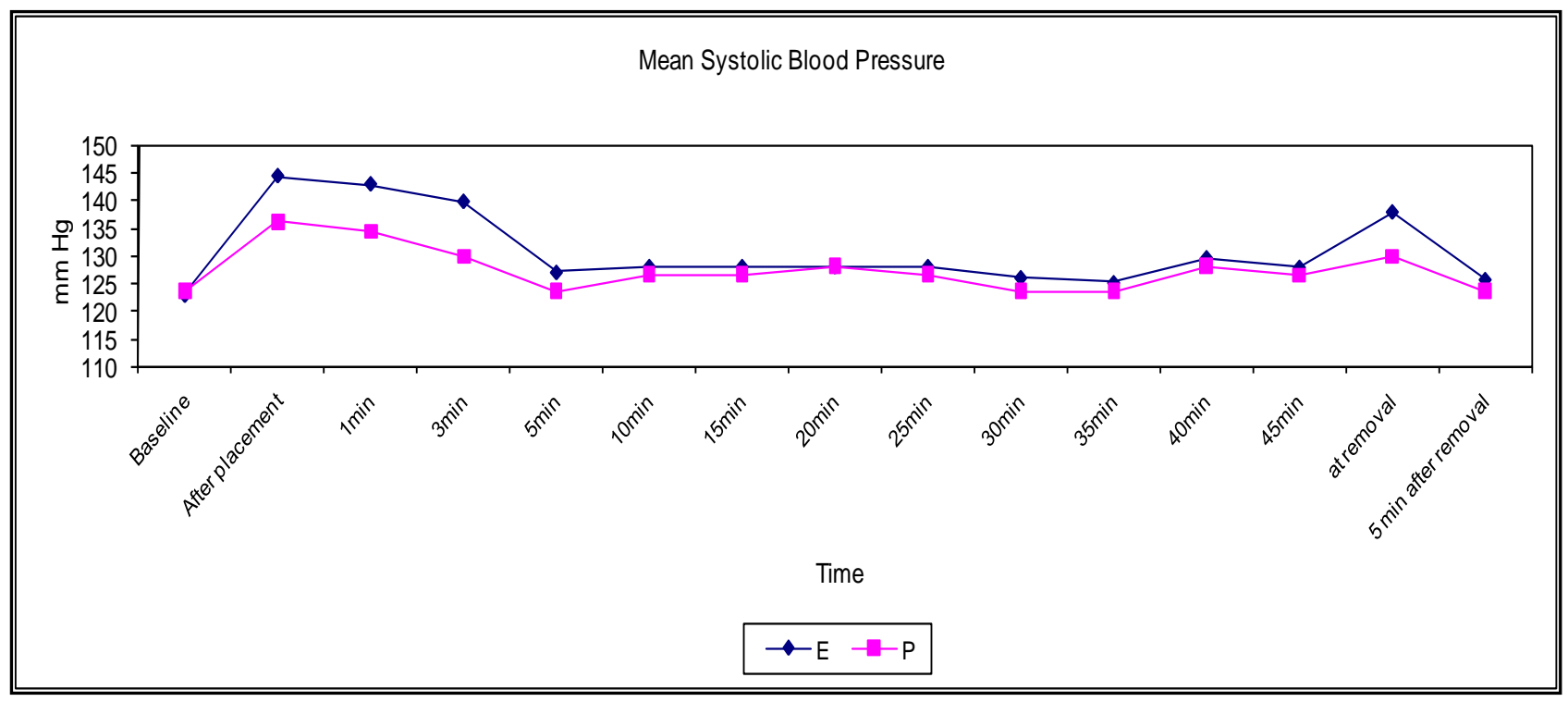

Graph 2: SBP Variation-Both the Groups

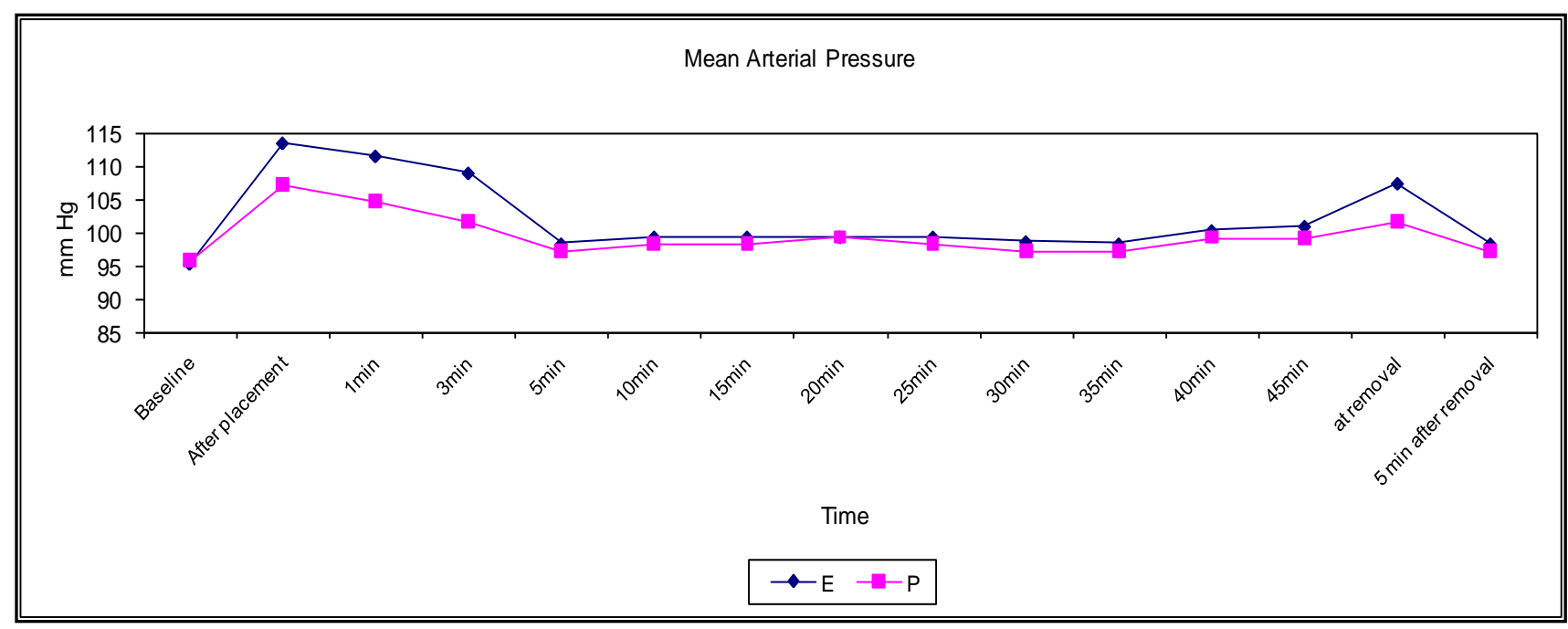

Graph 3: DBP Variation - Both the Groups

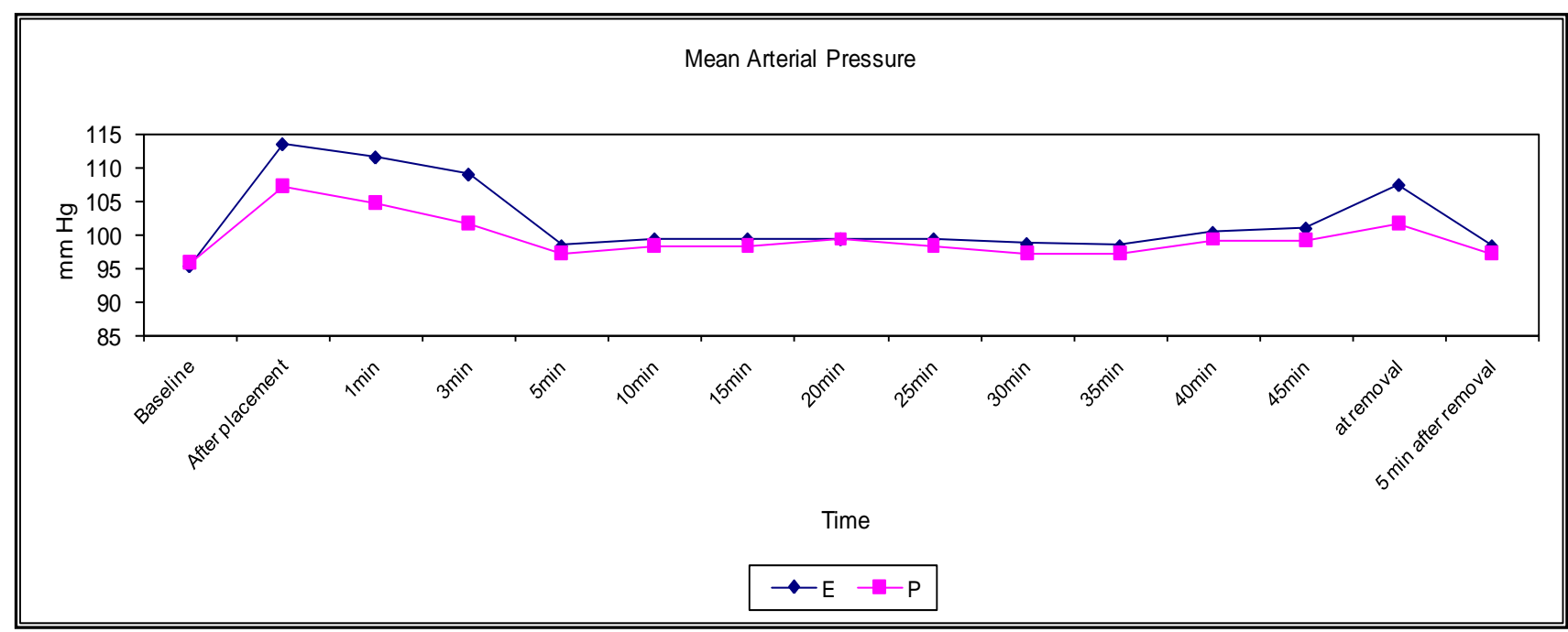


From graph no.-5, 6 it can be seen that $\mathrm{SpO}_{2}, \mathrm{ETCO}_{2}$ were well maintained in both the groups throughout the procedure. There was no significant difference of $\mathrm{SpO}_{2}$ and ETCO2 between the two groups at any point of time. $\mathrm{SPO}_{2}$ was maintained between $99.5 \%$ to $99.9 \%$ in both the groups where LMA-PS and ETT were used. $\mathrm{ETCO}_{2}$ varied from 33.6 to $43 \mathrm{mmHg}$ which was a good indicator of effective ventilation throughout the procedure.

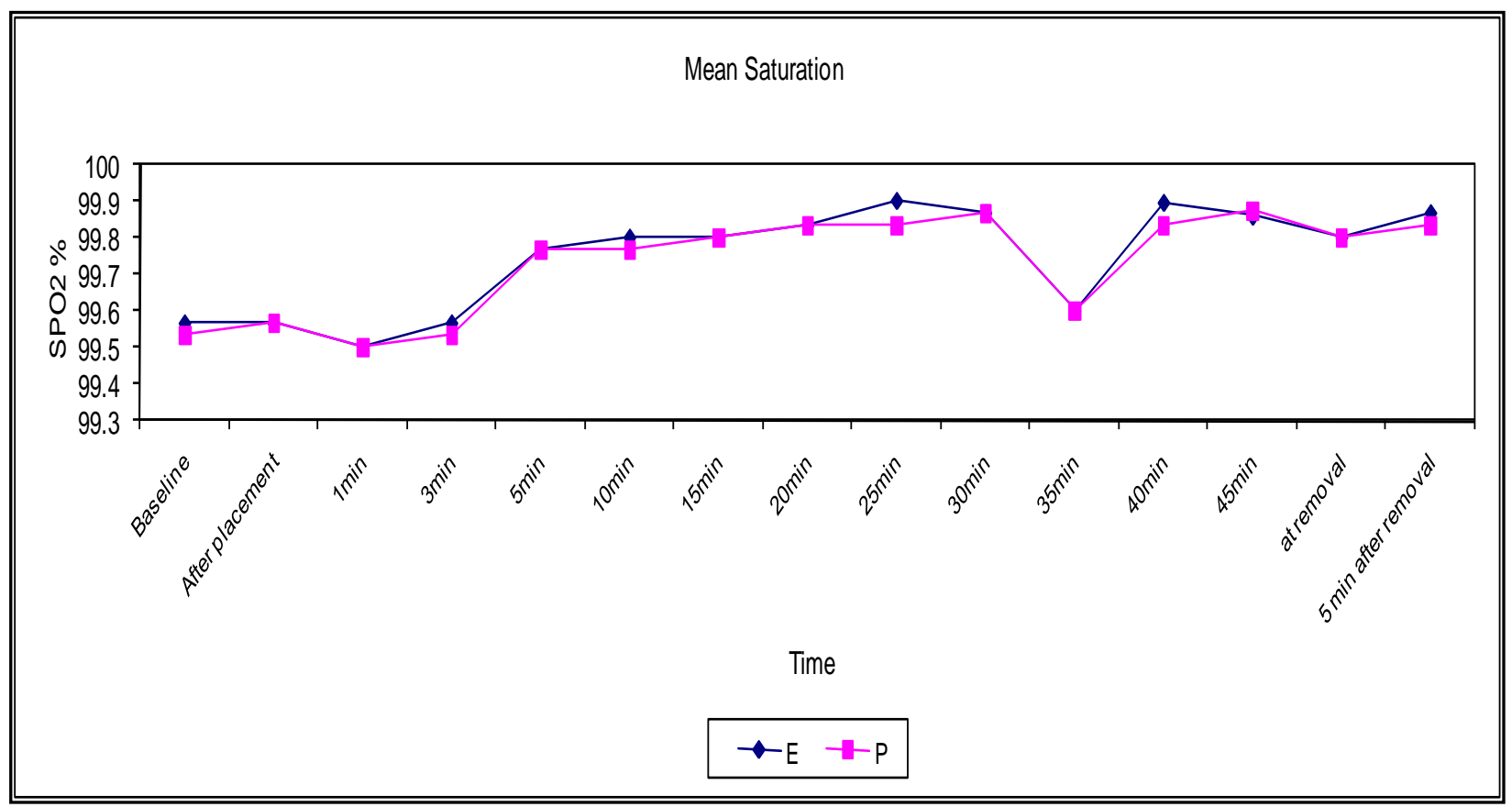

Graph 5: $\mathrm{SPO}_{2}$ Variation-Both the Groups

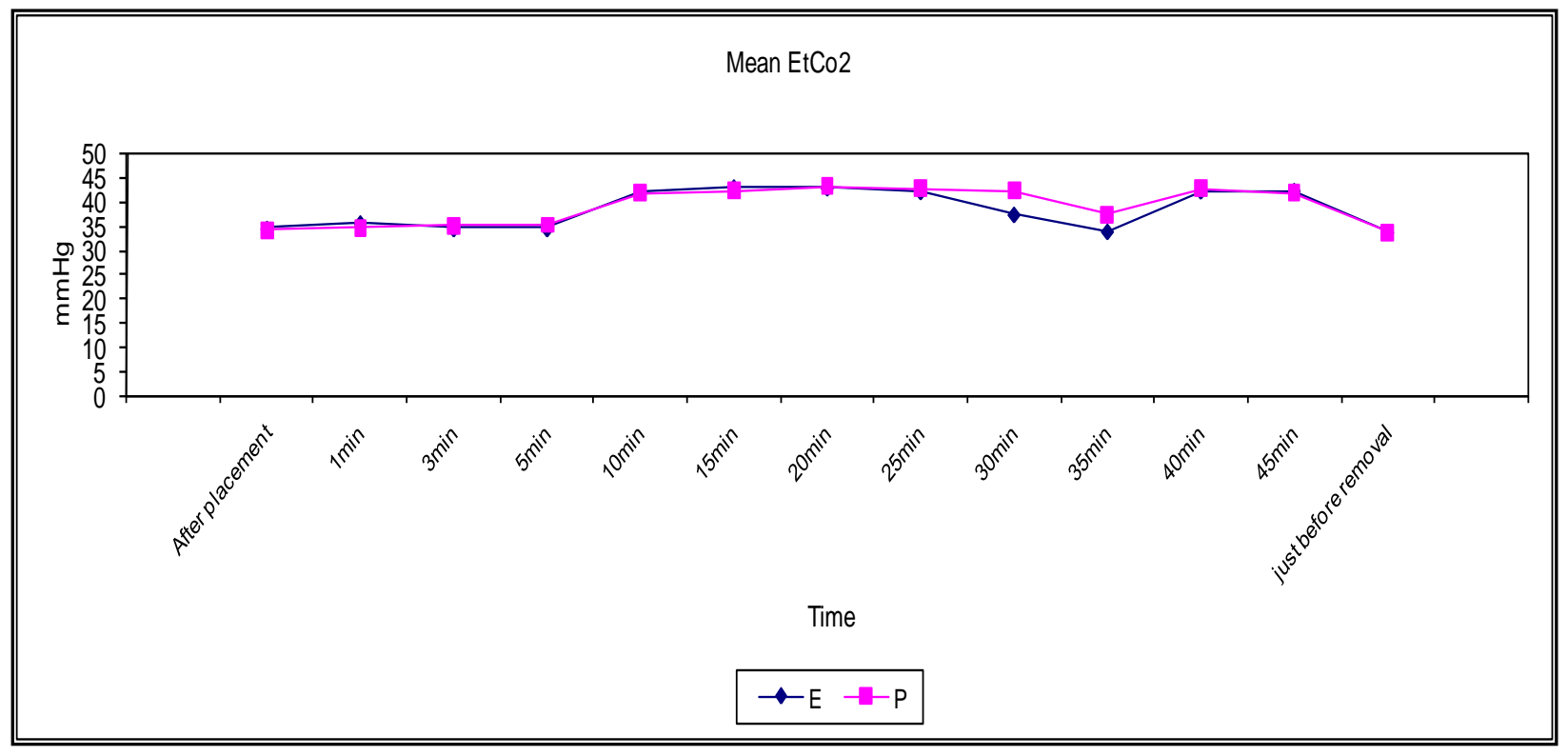

Graph 6: $\mathrm{ETCO}_{2}$ Variation-Both the Groups

\begin{tabular}{|c|c|c|c|c|c|c|}
\hline \multicolumn{7}{|c|}{ Complications } \\
\hline & $\begin{array}{c}\text { Sore Throat } \\
*\end{array}$ & \multicolumn{2}{c|}{$\begin{array}{c}\text { Gastric } \\
\text { Distension }\end{array}$} & \multicolumn{2}{c|}{ Aspiration } \\
\hline Group & - & + & - & + & - & + \\
\hline ETT & 26 & 4 & 30 & 0 & 30 & 0 \\
\hline $\begin{array}{c}\text { LMA- } \\
\text { PS }\end{array}$ & 27 & 3 & 30 & 0 & 30 & 0 \\
\hline Total & 53 & 7 & 60 & 0 & 60 & 0 \\
\hline \multicolumn{7}{|c|}{ Table 5 } \\
\hline
\end{tabular}

Fisher's exact test

From table 5, we can see that, in the ETT group 4 patients complained of sore throat immediately after removal of the device while in the LMA-PS group, 3 patients complained of the same. This was compared statistically by Fisher's exact test which showed to be insignificant $(\mathrm{P}>0.05)$. In both the groups, clinically detectable aspiration and gastric distension were not observed in any patient undergoing the procedure.

From our study, the LMA-PS has been proved to be an effective airway device in laparoscopic cholecystectomy 
providing positive pressure ventilation with very minimal sympathetic stimulation at insertion only. At removal of the LMA-PS, there was no sympathetic stimulation. LMA-PS has also been proved to have $100 \%$ success rate of insertion, Ryle's tube placement along with no significant complications during the operative procedure.

\section{DISCUSSION}

Airway management continues to be of paramount importance to anaesthesiologist. Till date, the cuffed tracheal tube was considered as the gold standard for providing a safe glottic seal, especially for laparoscopic procedures under general anaesthesia. ${ }^{6}$ Alternative airway management strategies have also been suggested to minimize these cardiovascular effects. ${ }^{7}$ The LMA-PS is a new entrant to the family of supraglottic airway devices. It has some added features over the LMA classic. ${ }^{8}$

This study was conducted with the aim of comparing LMA-PS as an alternative airway device to ETT, in terms of cardiovascular changes (Haemodynamic responses), efficacy of positive pressure ventilation, emergence and complications if any, in 60 patients undergoing laparoscopic cholecystectomy requiring higher airway pressures for adequate pulmonary ventilation, (Because of increased intraabdominal pressure from pneumoperitoneum). The LMA-PS has been proved to be adequate in previous studies by Sharma b. et al. 2003.6; Misra MN, 2008. ; Shroff P, 2006.10

IG Wilson et al. 1992 in a similar study found that the mean peak increase in heart rate were similar $(26.6 \%$ vs. $25.7 \%$ ) in the two groups but remained elevated for a longer duration in the ETT group like our study.11 Fujii et al. 1995 found that the pulse rate was consistently elevated for $3 \mathrm{~min}$ in LMA group and for 5 mins in ETT group. ${ }^{12}$

However, in their study they have taken both normotensive and hypertensive patients while we have included only normotensive patients. They also found that map increased immediately after both tracheal intubation and LMA insertion $(p<0.005)$. They remained elevated for 3 minutes after tracheal intubation in ETT group and for 1 minute after LMA insertion.

Similar to Fujii $Y$ et al. in our study SBP, DBP, MAP remained elevated for 3 minutes after tracheal intubation in group $\mathrm{E}$ and for 1 minute after LMA-PS insertion in group p. In a similar study by Sanjay Mu (1996) the rise in SBP was significantly high at the time of intubation and remained high even after 5 mins in ETT group in comparison to LMA group where increase was of lesser magnitude and persisted up to 3 minutes $^{13}$. In our study the rise in SBP was not sustained at 5 mins in group E (ETT), but instead came down towards baseline at $5 \mathrm{mins}$.

I.G. Wilson et al. (1992) in a similar study found that DBP compared with $\mathrm{t}=0$ (The onset of airway instrumentation defined at $\mathrm{t}=0$ ) increased significantly in ETT group at $0.5 \mathrm{mins}$ and $1 \mathrm{~min}$, but changes in LMA group did not reach significance. 11

In our study we found significant increase immediately after instrumentation in both group e and group P. Sanjay MU et al. (1996) in a similar study observed rise in DBP in both ETT and LMA group after placement of the airway devices.

Similar to our study, Fujii Y et al. (1995) also observed mean arterial pressure, which was significantly raised in both the groups. Jain M. K. et al. (2010) observed changes in
ABG/vital parameters during the use of ProSeal LMA as airway device in cases of laparoscopic cholecystectomy by using $\mathrm{CO}_{2}$ to create pneumoperitoneum. ${ }^{14}$ Hemodynamic response to insertion of PLMA was minimal as supported by Brimacombe JR. 2005, Lu PP et al. 2002, Evans NR et al. 2002, Figueredo E et al. 2003, El-Ganzouri A et al. 2003.15-19

Similar to our study that proved less haemodynamic alteration during removal of ProSeal LMA, Russo et al. (2009) also concluded that hemodynamic changes during extubation were significantly less pronounced during PLMA removal compared to the endotracheal tube removal in the ICU environment. ${ }^{20}$

Namita Saraswat, et al. 2011 did a prospective randomized study with the aim to compare the efficacy of ProSeal LMA and ETT in patients undergoing laparoscopic surgeries under general anaesthesia. There was no case of inadequate ventilation, regurgitation or aspiration. ${ }^{21}$

A properly positioned PLMA proved to be a suitable and safe alternative to ETT for airway management in elective fasted, adult patients undergoing laparoscopic surgeries. There was minimum haemodynamic stress response with PLMA when compared with endotracheal intubation. $8,22,23$

Bimla Sharma et al. (2008) used ProSeal LMA (PLMA) and demonstrated that the PLMA, is an efficient and safe airway tool for patients undergoing elective laparoscopic surgeries.

In our study, the LMA-PS when compared to the ETT proved to be an effective airway device providing PPV, with $100 \%$ success rate of LMA-PS insertion and Ryle's tube placement along with decreased incidence of complications during laparoscopic cholecystectomy as reported by previous workers doing similar studies for laparoscopic surgeries. ${ }^{15,16,22,24-31}$

Maltby JR et al. 2002 did their study with the purpose to compare LMA-PS with ETT with respect to pulmonary ventilation and gastric distention during laparoscopic cholecystectomy. Their result showed that there was no statistically significant difference in $\mathrm{SPO}_{2}$ or $\mathrm{ETCO}_{2}$ between the two groups before or during peritoneal insufflations in either non-obese or obese patients. Similar to our study they confirmed the correct placement of the LMA-PS when there was adequate chest expansion, chest auscultation and easy passage of gastric tube through the drain tube of the LMA-PS.

In a study of 100 adult patients undergoing laparoscopic surgery under general anaesthesia Sharma B, et al. 2003 reported that PLMA is an effective alternative airway for a wide range of laparoscopic surgical procedures. There were 3 cases of oesophageal regurgitation, but no incidence of pulmonary aspiration.

So we can interpret from the above discussion that both ETT and LMA-PS cause increase in hemodynamic response but the magnitude and duration of response is less in LMA-PS. This may be helpful particularly in vulnerable patients. Removal of LMA-PS showed that the change of HR, SBP, DBP, MAP were not significant to the baseline reflecting a smooth emergence.

\section{CONCLUSION}

We found that both the airway devices (LMA-PS and ETT) were $100 \%$ successful in the operative procedure (Laparoscopic cholecystectomy). In terms of haemodynamic responses and adequate pulmonary ventilation without gastric distention in all patients, without any significant complications. Both these 
devices have their own profile of complications which need to be dealt with vigilance and caution.

In experienced hands and following a strict protocol of insertion, the LMA ProSeal has been proved to be an efficient and safe alternative to Endotracheal tube for airway management of elective patients undergoing Laparoscopic Cholecystectomy.

\section{REFERENCES}

1. Forbes AM, Dally FG. Acute hypertension during induction of anesthesia and endotracheal intubation in normotensive man. Br J Anaesth 1970; 42:612-624.

2. Shribman AJ, Smith G, Achola J. Cardiovascular and catecholamine responses to laryngoscopy with or without tracheal intubation.

Br J Anaesth 1987;59:295-299.

3. Hassan HG, EL-Sharkawy TY, Renck H, et al. Haemodynamic and catecholamine responses to laryngoscopy with or without endotracheal intubation. Acta Anaesthesiol Scand 1991;35:442-447.

4. Derbyshire DR, Chmielewski A, Fell D, et al. Plasma catecholamine responses to tracheal intubation. $\mathrm{Br} \mathrm{J}$ Anaesth 1983;55:855-860.

5. Pennat JH. Anaes FRC, White PF. The laryngeal mask airway. Its uses in anaesthesiology. Anaesthesiology, 1993;79:144-63.

6. Sharma B, Sahai C, Bhattacharya A, et al. ProSeal laryngeal mask airway: A study of 100 consecutive cases of laparoscopic surgery.

Indian J Anaesth 2003;47:467-72.

7. Montazari K, Naghibi KH, Hasemi SJ. Comparison of hemodynamic changes after insertion of laryngeal mask airway, face mask and endotracheal intubation. Acta Medica Iranica 2004;42(6):437-440.

8. Brain AIJ, Verghese C, Strube PJ. The LMA "ProSeal"-a laryngeal mask with an esophageal vent. $\mathrm{Br} J$ Anaesth 2000;84:650-654.

9. Misra MN, Ramamurthy B. The Pro-Seal LMA TM and the tracheal tube: A comparison of events at insertion of the airway device. Internet J Anesthesiol 2008. Vol. 16. [Last accessed on 2010 Jul 9].

10. Shroff P, Surekha K. Randomized comparative study between the ProSeal laryngeal mask airway and the endotracheal tube for laparoscopic surgery. Internet J Anesthesiol 2006. Vol.11. [Last accessed on 2010 Jul 9].

11. Wilson IG, Fell D, Robinson SL, et al. Cardiovascular responses to insertion of the laryngeal mask. Anaesthesia 1992;47:300-2.

12. Fujii Y, Tanaka H, Toyooka H. Circulating responses to laryngeal mask airway insertion on tracheal intubation in normotensive and hypertensive patients. Canadian J Anaesth. Page 32-36, 1995 Jan.

13. Sanjay MU, Seema RB, Atul PK. Comparison of haemodynamic responses to laryngeal mask airway insertion and endotracheal intubation. J Anaes Clin Pharmaco 1996;12:279-281.

14. Jain MK, Venugopal M, Tripathi CB. Use of ProSeal LMA (PLMA) for Laparoscopic cholecystectomies: An ABG Analysis. Journal of Anaesthesiology Clinical Pharmacology 2010;26:87-90 (Issue -1).
15. Brimacombe JR. Laryngeal Mask Anesthesia. Principles and Practice. $2^{\text {nd }}$ ed. London: Saunders Elsevier Ltd.; 2005.

16. Lu PP, Brimacombe J, Yang C, et al. ProSeal versus the classic LMA for positive pressure ventilation during laparoscopic cholecystectomy. $\mathrm{Br} \quad \mathrm{J}$ Anaesth 2002;88:824-7. ( $\underline{\mathrm{s}})$

17. Evans NR, Gardner SV, James MFM, King JA, Roux P, Bennet $\mathrm{P}$, et al. The ProSeal laryngeal mask: results of descriptive trial with experience of 300 cases. $\mathrm{Br}$ J Anaesth 2002;88:534-9.

18. Figueredo E, Martinez M, Pintanel T. A comparison of the ProSeal TM laryngeal mask and the Laryngeal mask and the Laryngeal Tube ${ }^{\circledR}$ in spontaneously breathing anesthetized patients. Anesth Analg 2003;96:600-5.

19. El-Ganzouri A, Avramov MN, Budac S, et al. ProSeal laryngeal mask airway versus endotracheal tube: ease in insertion, hemodynamic, responses and emergence characteristics. Anesthesiology 2003;99:A571 (abstract).

20. Russo, Sebastian GMD, DEAA; Goetze, Benjamin MD; Troche, Stefan PhD; Barwing, Jürgen MD, DEAA, EDIC; Quintel, Michael MD; Timmermann, Arnd MD, DEAA, MME LMA-ProSeal ${ }^{\mathrm{TM}}$ for elective postoperative care on the intensive care unit: A Prospective, Randomized Trial. Anesthesiology; July 2009, Vol-111; issue -1. pp 116-121.

21. Namita Saraswat, Aditya Kumar, Abhijit Mishr, Amrita Gupta, Gyan Saurav, Uma Sribastab. The comparison of ProSeal Laryngeal Mask Airway and endotracheal tube in patients undergoing laparoscopic surgery under general anaesthesia. IJA, 2011;55:129-134.

22. Brimacombe J, Keller C. The ProSeal laryngeal mask airway. A randomized crossover study with the standard laryngeal mask airway in paralyzed, anesthetized patients. Anesthesiology 2000;93:104-109.

23. Cook TM, Nolan JP, Verghese C, Strube PJ, Lees M, Millar JR. Randomised cross over comparison of the ProSeal with the Classic laryngeal mask airway in unparalyzed anaesthetized patients. Br J Anaesth 2002;88:527-33.

24. Maltby JR, Beriault MT, Watson NC, et al. The LMAProSeal is an effective alternative to tracheal intubation for laparoscopic cholecystectomy. Canadian J Anesth 2002;49:857-62.

25. Natalini G, Lanza G, Rosano A, et al. Standard larngeal mask airway and LMA- ProSeal during laparoscopic surgery. J Clin Anesth 2003;15:428-32.

26. Garcia-Anuado R, Vivo Benlloch M, Zaragoza Fermandez C, et al. ProSeal laryngeal mask for laparoscopic cholecystectomy. Rev Esp Anestesiol Reanim 2003;50:55-7.

27. Roth H, Genzwuerker HV, Rothhaas A, et al. The ProSeal laryngeal mask airway and the laryngeal tube suction for ventilation in gynaecological patients undergoing laparoscopic surgery. Eur J Anesthesiol 2005;22;117-22.

28. Piper J, Fenn Wo, Rahn M, editors. Physiological equilibria of gas conites in the body. In: Hardbook of physiology> Ructions 3: Respiration. Washington, DC: American Physiological society; 1965.p 1205-20.

29. Sinha A, Sharma B, Sood J. ProSeal ${ }^{\mathrm{TM}}$ as an alternative to endotracheal intubation in pediatric laparoscopy. Pediatr Anesth 2007;17:327-32. 
30. Keller C, Brimacombe J. Mucosal pressure and oropharyngeal leak pressure with the ProSeal versus laryngeal mask airway in anaesthetized paralysed patients. Br J Anaesth 2000;85:262-266.
31. Bimla Sharma, Jayashree Sood, Chand Sahai, et al. Efficacy and safety performance of ProSeal laryngeal mask airway in laparoscopic surgery: Experience of 1000 cases. Indian Journal of Anaesthesia 2008;52(3):288296. 